Yayang Harigustian', Arlina Dewi' , Azizah Khoiriyati ${ }^{3}$

${ }^{1}$ Magister Keperawatan Universitas Muhammadiyah Yogyakarta, Alamat : Jl Lingkar selatan, Kasihan, Tamantirto,Bantul, Yogyakarta, 55183

${ }_{2}^{2}$ Magister Manajemen Rumahsakit Universitas Muhammadiyah Yogyakarta, Alamat : Jl Lingkar selatan, Kasihan, Tamantirto,Bantul, Yogyakarta, 55183

${ }^{3}$ Staf Pengajar Magister Keperawatan Universitas Muhammadiyah Yogyakarta, Alamat : Jl Lingkar selatan, Kasihan, Tamantirto,Bantul, Yogyakarta, 55183 E-mail : yayangharigustina@gmail.com

\section{Gambaran Karakteristik Pasien Gagal Jantung Usia 45 - 65 Tahun di Rumah Sakit PKU Muhammadiyah Gamping Sleman}

\section{Info Artikel:}

Masuk : 9 September 2016

Revisi : : 25 November 2016

Diterima : : 4 Desember 2016

DOI Number : 10.18196/ijnp.1152

\begin{abstract}
ABSTRAK
Penyakit gagal jantung merupakan penyakit yang dapat menyebabkan kematian. Sekitar 5,1 juta orang di Amerika Serikat mengalami gagal jantung. Tahun 2009, satu dari sembilan kematian di sebabkan karena menderita gagal jantung. Di Indonesia prevalensi penyakit gagal jantung tahun 2013 sebesar 0,13\%,estimasi jumlah penderita penyakit gagal jantung di Provinsi Daerah Istimewa Yogyakarta sebanyak 6.943 orang $(0,25 \%)$. Berdasarkan data Riskesdas tahun 2007 menunjukkan CHF merupakan penyebab kematian nomor tiga di Indonesia setelah stroke dan hipertensi. Tujuan penelitian ini untuk mengetahui karakteristik pasien gagal jantung usia 45 - 65 tahun di Poli Jantung RS PKU Muhammadiyah Gamping Sleman pada bulan September - November 2016. Penelitian dilakukan menggunakan penelitian deskriptif. Sampel penelitian 32 responden . Karakteristik pasien gagal jantung di Poli Jantung RS PKU Muhammadiyah Gamping Sleman yaitu umur responden paling tinggi rentang 61-65 tahun yaitu 59,38\%, jenis kelamin terbanyak adalah perempuan yaitu $53,12 \%$, pendidikan terahir terbanyak adalah SD yaitu 34,38\%, pekerjaan paling banyak adalah PNS yaitu 31,25\%, hampir semua responden stadium 2 yaitu 93,75\%. Kesimpulan dari penelitian ini yaitu sebagian besar responden berada pada usia 61 - 65 tahun,jenis kelamin responden lebih besar perempuan dari pada laki - laki, pendidikan terahir paling banyak sekolah dasar, pekerjaan sebagian besar pegawai negeri sipil, dan hampir semua responden mengalami gagal jantung stadium 2. Hasil penelitian ini diharapkan dapat mejadi acuan untuk mengetahui gambaran karakteristik pasien gagal jantung sehingga dapat dilakukan pencegahan ataupun intervensi untuk mengurangi kekambuhan pasien gagal jantung.

Kata Kunci :Karakteristik, Gagal Jantung.
\end{abstract}




\section{NURSING PRACTICES}

\section{ABSTRACT}

Heart failure is a disease that can caused death. About 5.1 million people in the United States had heart failure. In 2009, one in nine deaths caused by heart failure. In Indonesia, the prevalence of heart failure in 2013 was $0.13 \%$, the estimated number of heart failure patients in Yogyakarta was 6,943 (0.25\%). Based on data from 2007 indicated CHF Riskesdas the third cause of death in Indonesia after stroke and hypertension. The purpose of this study to determine the characteristics of heart failure patients in the Poly Heart Gamping Sleman PKU Muhammadiyah Hospital in September-November 2016. The study was conducted using a descriptive design. The sample was 32 respondents. Characteristics of patients with heart failure in Poly Heart PKU Muhammadiyah Hospital Gamping Sleman highest respondent's age range 6165 years was $59.38 \%$, the highest gender was female $53.12 \%$, the last education was elementary $34.38 \%$, the worst job many are civil servants was $31.25 \%$, stage 2 was $93.75 \%$. The conclusion of this study is that most of the respondents are at the age of 61-65 years old, the sex of the respondents is bigger than the male, the most recent primary school education, the work of most civil servants, and almost all respondents had heart failure stage 2 . The results of this study are expected to be a reference to know the description characteristics of patients with heart failure so that prevention or intervention can be done to reduce the recurrence of patients with heart failure.

Keywords: Characteristics, Heart Failure.

\section{PENDAHULUAN}

Congestive Heart Failure (CHF) atau sering dikenal dengan gagal jantung merupakan keadaan dimana jantung mengalami kegagalan dalam memompa darah untuk mencukupi kebutuhan nutrien dan oksigen sel - sel tubuh secara adekuat sehingga mengakibatkan peregangan ruang jantung (dilatasi) yang berfungsi untuk menampung darah lebih banyak untuk dipompakan keseluruh tubuh atau mengakibatkan otot jantung kaku dan menebal (Udjianti, 2010). Gejala khas pasien gagal jantung, yaitu : sesak nafas saat beristirahat atau beraktivitas, kelelahan, dan edema tungkai, sedangkan tanda khas gagal jantung adalah takikardia, takipnea, suara nafas ronki, efusi pleura, peningkatan vena jugularis, edema perifer dan hepatomegali (PERKI, 2015).

Penyakit gagal jantung merupakan penyakit yang dapat menyebabkan kematian. Sekitar 5,1 juta orang di Amerika Serikat mengalami gagal jantung. Tahun 2009, satu dari sembilan kematian di sebabkan karena menderita gagal jantung. Sekitar setengah dari orangorang yang menderita gagal jantung meninggal dalam waktu 5 tahun setelah didiagnosis. Perkiraan biaya yang dikeluarkan oleh negara pada pasien gagal jantung sebesar \$32 Milyar setiap tahun (Centers for Disease Control and Prevention, 2015).

Di Indonesia prevalensi penyakit gagal jantung tahun 2013 sebesar 0,13\% atau diperkirakan sekitar 229.696 orang, sedangkan berdasarkan gejala yang muncul sebesar 0,3\% atau diperkirakan sekitar 530.068 orang. Estimasi jumlah penderita penyakit gagal jantung di Provinsi Daerah Istimewa Yogyakarta sebanyak 6.943 orang (0,25\%) (Kementrian Kesehatan RI, 2014).

Kelangsungan hidup pasien dengan gagal jantung dipengaruhi beratnya kondisi yang dialami masing masing pasien. Setiap tahun mortalitas pasien dengan gagal jantung berat lebih dari $50 \%$, mortalitas pada pasien dengan gagal jantung ringan lebih dari 10 $\%$, sedangkan morbiditas pasien gagal jantung juga dipengaruhi oleh beratnya penyakit masing - masing pasien (Ball,1996 dalam Mutaqqin, 2009). Pasien dengan gagal jantung berat hanya mampu melakukan aktivitas yang sangat terbatas, sementara itu pasien dengan gagal jantung yang lebih ringan juga harus tetap melakukan pembatasan terhadap aktivitasnya. Pembatasan terhadap aktivitas menjadi salah satu penyebab pasien gagal jantung mempunyai kapasitas latihan yang menurun, walaupun pasien sudah menjalani pengobatan modern (Mutaqqin, 2009).

Berdasarkan hasil studi pendahuluan di PKU Muhammadiyah Gamping Sleman Yogyakarta jumlah pasien dengan gagal jantung pada tahun Tahun 2014 ada 472 pasien dan tahun 2015 ada 580 pasien, sedangkan jumlah pasien rawat jalan poli jantung dengan diagnosa gagal jantung setiap minggu ada $10-15$ pasien. 


\section{TUJUAN PENELITIAN}

Penelitian ini dilakukan untuk mengetahui karakteristik pasien gagal jantung di Poli Jantung RS PKU Muhammadiyah Gamping Sleman.

\section{METODE PENELITIAN}

Penelitian ini dilakukan menggunakan metode penelitian deskriptif. Penentuan sampling menggunakan non probability sampling dengan pendekatan consecutive sampling. Jumlah sampel pada penelitian 32 responden.

\section{HASIL PENELITIAN}

Karakteristik Pasien Gagal Jantung RS PKU Muhammadiyah Gamping Sleman Yogyakarta.

\begin{tabular}{|c|c|c|}
\hline Variabel & Jumlah & $\begin{array}{c}\text { Prosentase } \\
\text { (\%) }\end{array}$ \\
\hline \multicolumn{3}{|l|}{ Umur } \\
\hline 45-50 tahun & 7 & 21,88 \\
\hline 51-55 tahun & 1 & 3,12 \\
\hline 56-60 tahun & 5 & 15,62 \\
\hline 61-65 tahun & 19 & 59,38 \\
\hline \multicolumn{3}{|l|}{ Jenis Kelamin } \\
\hline Laki - laki & 15 & 46,88 \\
\hline Perempuan & 17 & 53,12 \\
\hline \multicolumn{3}{|l|}{ Pendidikan Terahir } \\
\hline Tidak Sekolah & 0 & 0 \\
\hline SD & 11 & 34,38 \\
\hline SLTP & 5 & 15,62 \\
\hline SLTA & 8 & 25 \\
\hline PT & 8 & 25 \\
\hline \multicolumn{3}{|l|}{ Pekerjaan } \\
\hline IRT & 7 & 21,875 \\
\hline PNS/Pensiun & 10 & 31,25 \\
\hline Wiraswasta & 7 & 21,875 \\
\hline
\end{tabular}

\begin{tabular}{|c|c|c|}
\hline Variabel & Jumlah & $\begin{array}{c}\text { Prosentase } \\
\text { (\%) }\end{array}$ \\
\hline Petani & 4 & 12,5 \\
\hline Swasta & 4 & 12,5 \\
\hline \multicolumn{3}{|l|}{ Stadium } \\
\hline Stadium 1 & 0 & 0 \\
\hline Stadium 2 & 30 & 93,75 \\
\hline Stadium 3 & 2 & 6,25 \\
\hline
\end{tabular}

\section{PEMBAHASAN}

Gagal jantung menjadi penyakit yang terus meningkat kejadiannya terutama pada lansia. Studi Framingham dalam penelitian Sani (2007) memberikan gambaran yang jelas tentang gagal jantung. Pada studinya disebutkan bahwa kejadian gagal jantung per tahun pada orang berusia $>45$ tahun adalah 7,2 kasus setiap 1000 orang laki-laki dan 4,7 kasus setiap 1000 orang perempuan. Di Amerika hampir 5 juta orang menderita gagal jantung (Sani, 2007).

Hasil penelitian menunjukkan bahwa rentang umur responden sebagian besar umur 61 - 65 tahun. Seiring dengan bertambahnya usia seseorang beresiko mengalami penyakit gagal jantung dikarenakan semakin bertambahnya usia maka terjadi penurunan fungsi jantung. hal ini didukung oleh penelitian yang dilakukan oleh Harikatang, Rampengan, \& Jim (2016) bahwa Kelompok usia terbanyak responden gagal jantung yang diteliti ialah kelompok 60-70 tahun dimana usia tersebut merupakan 50\% dari jumlah responden keseluruhan. Penelitian lain dilakukan oleh Sari, Rampengan \& Panda (2012),yaitu 30 kasus yang diteliti ditemukan 12 kasus (40\%) merupakan pasien dengan gagal jantung kronik berusia 60-69 tahun, kemudian disusul oleh kelompok umur 50-59 tahun dengan 11 kasus (37\%), kelompok umur 40-49 tahun dengan 4 kasus (13\%), dan yang paling sedikit adalah kelompok umur 30-39 tahun dengan 1 kasus (3\%).

Prevalensi gagal jantung sebagai salah satu penyakit kardiovaskuler menurut AHA (2012) di Amerika pada tahun 2008 dialami sekitar 5,7 juta untuk 


\section{NURSING PRACTICES}

semua tingkat usia. Distribusi penyakit $\mathrm{CHF}$ atau CHF kongestif meningkat pada usia 40 tahun keatas. Hal ini berkaitan dengan proses menua yang menyebabkan peningkatan proses aterosklerosis pada pembuluh darah. Aterosklerosis menyebabkan terganggunya aliran darah ke organ jantung sehingga terjadi ketidakseimbangan antara kebutuhan oksigen miokardium dengan suplai oksigen.

Menurut Hou, et al (2004) menyebutkan bahwa usia merupakan faktor risiko utama terhadap penyakit jantung dan penyakit kronis lainnya termasuk di dalamnya gagal jantung. Menurut Karavidas, et al (2010), pertambahan umur dikarakteristikkan dengan disfungsi progresif dari organ tubuh dan berefek pada kemampuan mempertahankan homeostasis. Hasil penelitian yang dilakukan oleh Ewika (2007) menunjukkan bahwa CHF atau CHF kongestif

paling banyak terjadi pada usia $<60$ tahun atau pada kelompok usia dewasa dibanding pada kelompok usia lanjut atau $>60$ tahun yaitu dengan persentase 55,55\%.

Responden pada kelompok intervensi dan kelompok kontrol antara jenis kelamin perempuan dan laki - laki memiliki jumlah yang hampir sama. Responden berjenis kelamin perempuan yaitu 17 orang (53\%) dan berjenis kelamin laki- laki yaitu 15 orang (47\%) dengan jumlah responden perempuan sedikit lebih banyak dari pada responden laki - laki. Penelitian yang dilakukan oleh Lupiyatama (2012), didapatkan jumlah pasien pria sebanyak $60(49,6 \%)$ dan pasien wanita sebanyak $61(50,4 \%)$, hasil ini juga sesuai dengan penelitian yang telah dilakukan oleh Biteker ( 2010), yaitu Pada didapatkan jumlah pasien gagal jantung pria dan wanita dengan jumlah yang hampir sama. Di negara - negara industri, CAD (Coronary Artery Disease) menjadi etiologi terbanyak gagal jantung kongestif pada pria dan wanita, yaitu sekitar $60-75 \%$, kemudian disusul oleh hipertensi dan penyebab lainnya (Mann, 2008).

Menurut penelitian yang dilakukan oleh Waty \& Hasan (2013), bahwa gagal jantung disebabkan paling banyak oleh $C A D$, disusul campuran antara HHD (Hipertensi Hearth Disease) dan CAD, dan
HHD. Di negara berkembang sepereti di Indonesia penyakit hipertensi berhubungan erat dengan kejadian gagal jantung (Cowie, 2008). Jenis kelamin pada perempuan lebih beresiko mengalami hipertensi. Hal ini berhubungan dengan faktor hormonal yang lebih besar dari dalam tubuh perempuan daripada pada laki laki. Faktor hormonal dapat menyebabkan peningkatan lemak dalam tubuh atau obesitas. Obesitas pada perempuan juga dapat disebabkan karena kurangnya aktivitas, lebih mudah stres pada perempuan dan lebih sering menghabiskan waktu untuk bersantai di rumah (Junaidi, 2010).

Hasil penelitian yang sesuai dengan penelitian ini adalah penelitian yang dilakukan Vani (2011), dimana didapatkan bahwa penyakit CHF lebih banyak terjadi pada perempuan dengan persentase 57,5\%. Perempuan lebih banyak menderita CHF pada penelitian ini disebabkan karena sebagian besar perempuan yang menjadi responden dalam penelitian ini telah berumur lanjut. Pada umur lanjut perempuan umumnya mengalami menopause, dimana pada saat itu kolesterol LDL meningkat yang menyebabkan perempuan lebih banyak menderita penyakit gagal jantung.

Responden pada kelompok intervensi sebagian besar yaitu 6 orang $(37,5 \%)$ pendidikan terahir SD (Sekolah Dasar), responden pada kelompok kontrol sebagian besar yaitu 5 orang $(31,25)$ pendidikan terahir SD (Sekolah Dasar) dan 5 orang $(31,25 \%)$ pendidikan terakhir PT (Perguruan Tinggi). Menurut penelitian yang dilakukan Agrina, Rini, \& Hairitama (2011), seseorang yang memiliki pendidikan lebih tinggi akan mudah menyerap informasi dan memiliki pengetahuan yang lebih baik dari pada seseorang dengan tingkat pendidikan yang rendah. Semakin tinggi pendidikan yang dimiliki seseorang maka semakin mudah menerima informasi yang diberikan. Penelitian lain dilakukan oleh Bradke (2009), bahwa salah satu faktor yang dapat mempengaruhi pasien dirawat inap berulang pada pasien gagal jantung di rumah sakit adalah rendahnya tingkat pendidikan.

Sebagian besar responden yaitu 10 orang $(31,25 \%)$ bekerja sebagai PNS (Pegawai Negri Sipil). Menurut Atika 
(2016), etos kerja dan kinerja yang tinggi sulit dicapai apabila PNS mengalami stress kerja. Seseorang yang mengalami stress mempunyai resiko terkena penyakit hipertensi, hipertensi dapat menyebabkan terjadinya hipertrofi ventrikel kiri yang dihubungkan dengan terjadinya disfungsi diastolik dan meningkatkan resiko gagal jantung. Pekerjaan yang berat, terus menerus dan kurang beristirahat dapat meningkatkan kerja jantung dalam memompa darah ke seluruh tubuh untuk memenuhi kebutuhan tubuh dalam beraktivitas (Kaplan dan Schub, 2010). Pekerjaan yang berat diketahui dapat menjadi beban dan menyebabkan terjadinya gangguan kesehatan, terutama pada sistem kardiovaskuler (Rochmi, 2010 dalam Yenni et all, 2014).

Responden hampir semuanya menderita gagal jantung stadium 2. Penelitian yang dilakukan oleh Sari, Rampengan \& Panda (2012), ditemukan pasien yang datang berobat ke Poliklinik Jantung dengan kelas fungsional II atau sekitar 43\% dengan gejala berupa palpitasi dan dispnea timbul pada saat aktifitas fisik biasa. Penelitian lain dilakukan Pudiarifanti, Pramantara \& Ikawati (2015) sebagian besar yaitu 73\% responden stadium 2 dan $52 \%$ responden menderita gagal jantung $>1$ tahun. Fungsi jantung pada penderita gagal jantung stadium 2 mengalami penurunan dan terjadi penurunan cardiac out put. Penurunan cardiac out put akan membuat jantung terkompensasi untuk bekerja lebih kuat dengan harapan mampu memenuhi kebutuhan tubuhnya, tetapi dengan kronisnya kondisinjantung semakin gagal dalam memompa (Mariyono \& Santoso, 2007).

\section{KEKURANGAN PENELITIAN}

Kekurangan pada penelitian ini yaitu pengambilan sampel dengan jumlah yang tidak banyak yaitu 32 responden.

\section{KESIMPULAN}

Hasil Penelitian ini telah mengidentifikasi karakteristik umur, jenis kelamin, pendidikan terahir, pekerjaan, dan stadium gagal jantung. Sebagian besar responden berada pada usia 61 - 65 tahun,jenis kelamin responden lebih besar perempuan dari pada laki - laki, pendidikan terahir paling banyak sekolah dasar, pekerjaan sebagian besar pegawai negeri sipil, dan hampir semua responden mengalami gagal jantung stadium 2. Hasil penelitian ini diharapkan dapat mejadi acuan untuk mengetahui gambaran karakteristik pasien gagal jantung sehingga dapat dilakukan pencegahan ataupun intervensi untuk mengurangi kekambuhan pasien gagal jantung. Peneliti selanjutnya dapat melakukan penelitian dengan memberikan sebuah intervensi untuk pasien gagal jantung dengan jumlah sampel yang lebih besar.

\section{REFERENSI}

Agrina, Rini,S., \& Hairitama, R. (2011). Kepatuhan Lansia Penderita Hipertensi dalam Pemenuhan Diet Hipertensi. Riau : Universitas Riau.

American Hearth Asosiation.(2012). Heart disease and stroke statistic. http://ahajournal.org.com.

Atikah. (2016). Hubungan Antara Prokastitansi Kerja Dengan Stres Kerja Pada PNS. Universitas Muhamadiyah Surakarta.

Biteker M, Duman D, Dayan A, Can Mustafa M, Tekkeşin Ilker A.(2011). Inappropriate use of digoxin in elderly patients presenting to an outpatient cardiology clinic of a tertiary hospital in turkey. Türk Kardiyol Den arş. 2011;39(5):366.

Bradke, P. (2009). Transisi depan program mengurangi readmissions untuk pasien gagal jantung.

http://www.inovations.ahrq.gov/content. aspx\%3Fid\%3D2206.

Centers for Disease Control and Prevention (CDC). (2015). Heart Failure Fact Sheet. Departement of Health and Human Services USA. http://www.cdc.gov/dhdsp/ data_statistics/fact_sheets/fs_heart_failure.htm

Cowie, M.R., Dar, Q., (2008). The Epidemiology and Diagnosis of Heart Failure. In: Fuster, V., et al., eds. Hurst's the Heart. 12th ed. Volume 1. USA: McGrawHill, 713.

Ewika, D. N. A. (2007). Perbedaan etiologi gagal jantung kongestif usia lanjut dengan usia dewasa di Rumah Sakit Kariadi Januari - Desember 2006. eprints.undip. ac.id/22675/1/Desta.Pdv 


\section{NURSING \\ PRACTICES}

Harikatang,A., Rampengan,S., \& Jim, E.(2016).Hubungan antara jarak tempuh tes jalan 6 menit dan fraksi ejeksi pada pasien gagal jantung kronik terhadap kejadian kardiovaskular. Jurnal e-Clinic (eCl), Volume 4, Nomor 1, Januari-Juni 2016.

Hou, N.(2004). Relationship of age and sex to health-related quality of life in patients with heart failure. Am J Crit Care 2004 March; 13(20:153-61).

Junaidi,I. (2010). Hipertensi : Pengenalan, Pencegahan, dan Pengobatan. Jakarta : PT Bhuana Ilmu Populer.

Kaplan \& Schub. (2010). Hearth Failure In Women. Cinahl Information System. 1:57-63.

Karavidas, et al. (2010). Aging and the cardiovaskular system. Hellenic Journal of Cardiology. 51-421-427.

Kementrian Kesehatan RI. (2014). Situasi Kesehatan Jantung. Pusat Data dan Informasi Kementrian Kesehatan RI.

Lupiyatama, S.(2012). Gambaran Peresepan Digoksin pada Pasien Gagal Jantung yang Berobat Jalan di RSUP dr. Kariadi Semarang. Karya Tulis Ilmiah. Program Pendidikan Sarjana Kedokteran Fakultas Kedokteran Universitas Diponegoro Semarang.

Mann, D.L..(2008). Heart Failure and Cor Pulmonale. In: Fauci, A.S., et al., eds. Harrison's Principles of Internal Medicine. Volume 2. 17th ed. USA: McGraw-Hill, 1443.

Mariyono \& Santoso. (2009). Definisi, Klasifikasi, Diagnosis dan Penanganan Gagal Jantung. RSUP Sanglah, Denpasar. http://download.portalgaruda.org/article. php?article $=13160 \&$ val=927 akses 11 Maret 2017 .

Muttaqin, Arif. (2009). Asuhan Keperawatan Klien dengan Gangguan Sistem Kardiovaskuler dan Hematologi. Jakarta : Salemba Medika.

Notoatmodjo,S.(2007). Metodologi Penelitian Kesehatan. Jakarta : Rineka Cipta.

Perhimpunan Dokter Spesialis Kardiovaskuler Indonesia (PERKI). (2015). Pedoman Tata Laksana Gagal Jantung. National Cardiovascular Center Harapan Kita Hospital. Pudiarifantil, N., Pramantara,D., \& Ikawati,Z. (2015).Faktorfaktor yang Mempengaruhi Kualitas Hidup Pasien Gagal Jantung Kronik. Jurnal Manajemen dan Pelayanan Farmasi. Volume 5 Nomor 4 - Desember 2015. p-ISSN: 2088-8139. e-ISSN: 2443-2946.
Sani, A.(2007).Heart Failure : Current Paradigm. Jakarta : Medya Crea. Cetakan Pertama.

Sari, P., Rampengan, S.H \& Panda, S. (2012).Hubungan Kelas NYHA dengan Fraksi Ejeksi pada Pasien Gagal Jantung Kronik di bBLU/RSUP Prof. dr. r.d. Kandou Manado. Fakultas Kedokteran Universitas Sam Ratulangi Manado.

Slater, M Renee.,Phillips Denise M.,Elizabeth K (2008). Cost effective care a phone call a nurse management telephonic pragram for patient chronic heart failure. Journal of Nursing economics OI, 26/No1.

Udjianti, Wajan Juni. (2010). Keperawatan Kardiovaskuler. Jakarta : Salemba Medika.

Vani, S. C. (2011). Penyakit penyerta dan gaya hidup pada penyakit Congestive Heart Failure (CHF) di RS. Dr. Wahidin Sudirohusodo dan RS.Stella Maris Makassar. http:// repository.unhas.ac.id/bitstream/handle/123456789/385/ BAB\%20V\%20Vani.docx?sequence $=3$

Waty,M \& Hasan, H. (2013). Prevalensi Penyakit Jantung Hipertensi pada Pasien Gagal Jantung Kongestif di RSUP H.Adam Malik Prevalence of Hypertensive Heart Disease in Congestive Heart Failure Patients at RSUP H.Adam Malik. E-Journal FK USU Vol 1 No 1, 2013.

Yenni, E.,Nurchayati.S., \& Sabrian.F.(2014). Pengaruh Pendidikan Kesehatan Latihan Rehabilitasi Jantung terhadap Pengetahuan dan Kemampuan Mobilisasi Dini pada Pasien Congestive Heart Failure (CHF). Program Studi Ilmu Keperawatan Universitas Riau. 